\title{
IL-6 production of $\mathrm{C} 2 \mathrm{C} 12$ cells is enhanced in the presence of macrophages and pravastatin
}

\author{
Karolina Cseri ${ }^{1,2}$, Péter Szentesi ${ }^{1}$ and László Csernoch ${ }^{1}$ \\ ${ }^{1}$ Department of Physiology, Faculty of Medicine, University of Debrecen, Hungary \\ ${ }^{2}$ Doctoral School of Molecular Medicine, University of Debrecen, Debrecen, Hungary
}

\begin{abstract}
Skeletal muscle secrets several bioactive molecules known as myokines. Interleukin-6 (IL-6) has been described as a myokine secreted in response to skeletal muscle injury as well as to macrophage invasion in inflammation. To our knowledge no connection between macrophages and skeletal muscle regarding IL-6 secretion has been described so far. Here we report that co-culturing of C2C12 cells with RAW macrophages enhances IL-6 secretion of the cells cultured together. However, this is not seen in cross-feeding experiments, where culture medium of RAW macrophage culture is used as the culture medium of $\mathrm{C} 2 \mathrm{C} 12$ cells or vice versa. Pravastatin, known to induce myopathy, also stimulates IL-6 production in monocultured C2C12 cells and elevates IL- 6 concentration in the culture medium of the co-cultures. These results indicate an intricate interaction between skeletal muscle and macrophages in inflammation related to IL-6 production.
\end{abstract}

Key words: Skeletal muscle - Macrophages - Co-culture - IL-6 - Pravastatin

\section{Introduction}

Skeletal muscle is one of the most flexible tissues with high regenerative capacity. Following muscle injury, myogenesis starting from muscle stem cells (satellite cells) in adult skeletal muscle involves the proliferation of myoblasts, fusion, and transformation into differentiated myotubes and myofibers (Dumont et al. 2015). In vivo the nearer and farer surroundings (niche) of the muscle cells, including macrophages, play very important role in the regulation of these subsequent processes. In the acute phase of regeneration, tissue resident macrophages and bone marrow-derived monocytes infiltrate the injured area playing a scavenger role and secreting humoral factors (Yin et al. 2013).

Myogenesis during regeneration can be modelled in cell culture starting from satellite cells derived from adult skeletal muscle (Nag and Foster 1981) or by using immortalized cell lines. Monocyte/macrophage cell lines can also be cultured, so one possibility to study the interaction between myogenic

Correspondence to: Laszlo Csernoch, Department of Physiology, Faculty of Medicine, University of Debrecen, Nagyerdei krt. 98, Debrecen, Hungary, H-4002

E-mail: csl@edu.unideb.hu and myeloid cells and model the inflammatory myopathies in vitro is the usage of skeletal muscle-macrophage co-cultures (Cantini and Carraro 1995). In our experiments C2C12 murine skeletal muscle and RAW 264.7 mouse macrophage cell lines were cultured together to investigate the interaction between myogenic cells and macrophages during proliferation and differentiation processes.

It is widely accepted that myogenic and immune cells interact with each other under both physiological and pathological conditions. Communication between the cells is mediated mainly by soluble factors (cytokines, chemokines) but direct cell-to-cell crosstalk may also be hypothesized (Merely et al. 1999; Pillon et al. 2013; Yin et al. 2013).

It has recently been reviewed by Dort and his coworkers (2019) that macrophages play a crucial role in skeletal muscle regeneration. Myogenic cells (satellite cells, myoblasts, and myotubes) also release a series of myokines that act as autocrine or paracrine regulators in different steps of regeneration (Tidball and Villalta 2010; Wosczyna and Rando 2018).

In the muscle regeneration, the interleukin-6 (IL-6) plays crucial role as a key regulator. IL-6 as a proinflammatory cytokine is released from M1 macrophages (Cantini et al. 1995; Wang et al. 2008) and as a myokine released from the myogenic cells (Serrano et al. 2008). It regulates skeletal 
muscle regeneration and hypertrophy by controlling the proliferative capacity of muscle stem cells. Muscle stress is followed by satellite cell's activation, proliferation, differentiation, and completed by the fusion of satellite cells forming new myofibers. IL- 6 can be released by either infiltrating inflammatory cells and/or by cell satellite or myofibers in the muscle. IL- 6 release might initiate and regulate the different actions of satellite cells during myogenesis. Beside the aforementioned role of IL- 6 in the myogenesis, its regulator function in pathological conditions is also hypothesized. It was reported by Carson and Baltgalvis (2010) that the systemic IL-6 levels were found to be elevated chronically in many type of cancers that may inducing cachexia. It was suggested that the increased level of IL- 6 could cause the decrease in muscle mass.

Statins are the most effective, widely used drugs in hypercholesterolemia for reducing the level of low-density lipoprotein cholesterol and triglycerides by inhibiting 3-hydroxy-3methyl coenzyme A (HMG-CoA) reductase thus blocking the key enzyme of the synthesis of cholesterol (Evans and Rees 2002; Thompson et al. 2003).

Beside their therapeutic advantages, statins may rarely induce serious muscle related adverse effects (Walsh and Amato 2005; Dalakas 2009; Nazir et al. 2017). Statininduced myopathy, according to its pathogenesis, can either be toxic non-autoimmune or statin-induced necrotizing autoimmune myopathy (SINAM). Toxic myopathy can be focal or generalized (Walsh and Amato 2005; Dalakas 2009), severity of symptoms is dose-dependent (Davidson et al. 1997). SINAM is a rare and severe form of druginduced myopathy in which statin treatment initiates an autoimmune process which cannot be reversed by drug withdrawal (Pasnoor et al. 2014). We have previously shown that statin treatment decreased the proliferation and fusion of skeletal myotubes in cell culture (Füzi et al. 2012) and negatively regulated calcium homeostasis of adult skeletal muscle fibers (Vincze et al. 2015). These effects can contribute to the observed myopathies in statintreated patients.

Besides the direct action of statins on muscle cells, their effects on the macrophages may also play a pathogenic role in statin-induced myopathy (Stenzel et al. 2012). It was reported by Fu et al. (2019) that fluvastatin had no effect on freshly isolated monocytes but increased the IL-6 production of differentiated macrophages.

The aim of the present study was to investigate the interaction between myogenic cells and macrophages cultured together in terms of proliferation rate and IL- 6 production. Using muscle-macrophage co-culture as a model of statin-induced myopathy, effects of pravastatin on myogenic proliferation and differentiation as well as IL-6 production were studied in mono- and co-cultures of $\mathrm{C} 2 \mathrm{C} 12$ cells and RAW macrophages.

\section{Materials and Methods}

\section{Cell culturing}

Murine $\mathrm{C} 2 \mathrm{C} 12$ skeletal muscle cell line was obtained from the European Collection of Cell Cultures (ECACC). RAW 264.7 mouse macrophage cell line (American Type Culture Collection) was a kind gift of Prof. L. Virágh (Department of Medical Chemistry, University of Debrecen, Debrecen, Hungary). Cells were cultured in Dulbecco's Modified Eagle's Medium (DMEM-high glucose, Sigma-Aldrich, St. Louis, MO, USA) supplemented with $50 \mathrm{U} / \mathrm{ml}$ penicillin, $50 \mu \mathrm{g} / \mathrm{ml}$ streptomycin, $10 \%$ fetal bovine serum (FBS) for proliferation and $2 \%$ horse serum (HS) for myoblast differentiation and were kept at $37^{\circ} \mathrm{C}$ in an atmosphere containing $5 \% \mathrm{CO}_{2}$. Medium was changed to fresh in every second day.

\section{Cell culturing protocol for examination of the proliferation of co-cultures}

For monitoring the proliferation in the co-culture, $10^{5} \mathrm{C} 2 \mathrm{C} 12$ cells in $200 \mu \mathrm{l}$ medium were seeded on the marginal zone of a $3 \mathrm{~cm}$ petri dish, and $5 \times 10^{3}$ RAW264.7 cells in $100 \mu \mathrm{l}$ medium were seeded on the center of the same dish. When cells were settled to the surface, $2 \mathrm{ml}$ culture medium was added after a gentle rinse with phosphate buffered saline (PBS). Hence, the two cell types were cultured together without direct cellcell contact for a while. Monocultures were seeded in the same manner for accurate comparison. Medium was changed every second day. Cells were stained with May-Grünwald and Giemsa solution according to the protocol. At the bottom of the plastic cell-culture plate $\mathrm{C} 2 \mathrm{C} 12$ cells were washed 3 times with PBS, fixed in methanol for $5 \mathrm{~min}$ and stained with Giemsa solution (Molar Chemicals Kft, Halásztelek, Hungary) for $5 \mathrm{~min}$. Next, May-Grünwald (25× dilution in tap water) solution (Molar Chemicals Kft) was added to the cells. 15 min later cells were washed in tap water and let dried. Photos were taken by a cell imaging system (EVOS FLC Cell Imaging System, Thermo Fischer Scientific, Waltham, MA, USA) and were analyzed with ImageJ software (NIH, Bethesda, MD, USA) to determine the area covered by cells.

\section{Cell culturing protocol for monitoring the IL-6 production of co-cultures}

$5 \times 10^{2}$ C2C12 cells and 50 RAW264.7 macrophages were mixed and seeded on a 96-well-plate in $200 \mu \mathrm{l}$ proliferating medium. On day 3 growth medium was exchanged to one supplemented with $2 \%$ HS to facilitate myoblast differentiation. On day $1,3,5,7$, and 9 culture medium were collected, centrifuged $(2000 \mathrm{rpm}, 5 \mathrm{~min})$ and stored at $-80^{\circ} \mathrm{C}$ until further use. For proper comparison, C2C12 and RAW 264.7 cell monocultures were seeded and handled in the same manner. 
"Cross-feeding" experiment on cell cultures

On the $5^{\text {th }}$ day after seeding RAW 264.7 or C2C12 cells on 96-well-plates, culture medium was collected from monocultures, centrifuged (2000 rpm, $5 \mathrm{~min}$ ), the supernatant was filtered $(0.22 \mu \mathrm{m}$ sterile syringe filter, Sigma-Aldrich). Half the volume of $\mathrm{C} 2 \mathrm{C} 12$ cell culture medium supplemented with equal amount of fresh medium was added onto RAW 264.7 macrophages, and vice versa. After 24-h culturing, on day 6 , the culture medium was collected again, centrifuged, filtered as previously described and used for ELISA measurement. Culture medium from parallel co-culture without cross-feeding was used as control.

\section{IL-6 cytokine measurement by ELISA}

Concentration of IL- 6 in cell culture medium was determined by commercially available ELISA kit according to the manufacturer's instructions (Murine IL-6 ELISA Set, Diaclone Research, France). For testing we used 3 biological replicates.

\section{IL-6 fluorescent staining}

Co-cultured cells were treated with $3 \mu \mathrm{g} / \mathrm{ml}$ Brefeldin-A (Sigma-Aldrich) for $1 \mathrm{~h}$ to inhibit the protein transport from the endoplasmic reticulum to the Golgi apparatus. Cells were washed three times in PBS and fixed in 4\% paraformaldehyde (PFA) (pH 7.4) for $15 \mathrm{~min}$ at room temperature. After quenching formaldehyde crosslinking reaction with glycine (30 mM glycine in PBS, pH 7.4, 5 min) cells were permeabilized with $0.5 \%$ TritonX-100 in PBS for 20 min. Non-specific binding sites were blocked for $1 \mathrm{~h}$ (Serum free protein block, Dako, Carpinteria, CA), then with primary antibody against IL-6 (Cat.no.NB600-1131, Novus Biologicals, Littleton, CO, USA) overnight at $4^{\circ} \mathrm{C}$. Cells were washed three times in $0.1 \%$ Tween-20 in PBS and incubated with secondary antibody (Cat.no. A32731, Invitrogen, Life Technologies, San Francisco, CA, USA) for $1 \mathrm{~h}$ at room temperature. After washing three times in PBS cells were covered by Mowiol 4-88 (Cat.no. 81381, Sigma-Aldrich, Dorset, UK) and glass coverslips. Only positivity of staining was evaluated without quantitative measurement of fluorescence intensity.

\section{Cell culturing and pravastatin treatment protocol for IL-6 cytokine assay}

$10^{5} \mathrm{C} 2 \mathrm{C} 12$ cells were seeded on 24-well-plates in $2 \mathrm{ml}$ growth medium and on day 3 the medium was changed to medium extended with $2 \%$ HS to start myoblast differentiation. On day 6 , when cultures contained considerable amount of myotubes, $5 \times 10^{4}$ RAW 264.7 macrophage cells were seeded on muscle cells, and the co-culture was treated with 500 $\mu \mathrm{M}$ pravastatin (Cat.no. P4498, Sigma-Aldrich) for $24 \mathrm{~h}$ in serum-free DMEM. Culture medium was collected, centrifuged, and stored at $-80^{\circ} \mathrm{C}$ until use. For proper comparison monocultures were cultured and handled in the same manner. Non-treated cells were used as controls.

\section{Cell culturing and pravastatin treatment protocol for the examination of cell proliferation}

$10^{3}$ C2C12 cells and $5 \times 10^{2}$ RAW 264.7 macrophages were seeded on 96-well-plates in monocultures. After cells settled to the bottom of the plate, $500 \mu \mathrm{M}$ pravastatin was added to the wells in growth medium containing 10\% FBS. After $24 \mathrm{~h}$, photos of the wells were taken, and the area covered by cells was determined by ImageJ software.

\section{Cell culturing and pravastatin treatment protocol for the examination of $\mathrm{C} 2 \mathrm{C} 12$ cells differentiation}

$5 \times 10^{2} \mathrm{C} 2 \mathrm{C} 12$ cells were seeded on 96-well-plates in $10 \% \mathrm{FBS}$ containing growth medium. On day 3 medium was changed to low serum containing differentiating medium, and on day 4 pravastatin $(500 \mu \mathrm{M})$ was added to the cells. On day 5, 7, and 9 treated and non-treated control cells were washed carefully in PBS and stained according to May-Grünwald Giemsa. Starting at day 4 culture medium was changed in every second day to fresh medium with or without pravastatin (treated and non-treated cultures, respectively). Photos of the cultures were taken, and the number of myotubes and the stained nuclei were counted.

\section{Measurement of cell viability using MTT-assay}

On day 7 of culturing we determined the viability of control and pravastatin treated C2C12 cells by MTT assay (Sigma-Aldrich). Briefly, in metabolically active cells mitochondrial dehydrogenases reduce the yellow MTT to bluish formazan product. Cells were incubated with $0.01 \% \mathrm{MTT}$ reagent for $30 \mathrm{~min}$ at $37^{\circ} \mathrm{C}$ in an atmosphere containing $5 \% \mathrm{CO}_{2}$. After incubation, culture medium was discarded, and cells were lysed in $100 \mu \mathrm{LMSO}$. Solubilized cells were transferred to a clear ELISA plate and optical density was measured at $550 \mathrm{~nm}$. The absorbance obtained from pravastatin-treated cells was expressed as a percentage of that obtained from untreated control cells.

\section{Statistical analysis}

All data are representative of at least three independent experiments. Averages are expressed as mean \pm standard deviation (SD). Differences were assessed using one-way analysis of variance (ANOVA) and all pair wise multiple comparison procedures (Bonferroni multiple comparison). In some cases unpaired T-test was used. A p-value of less 


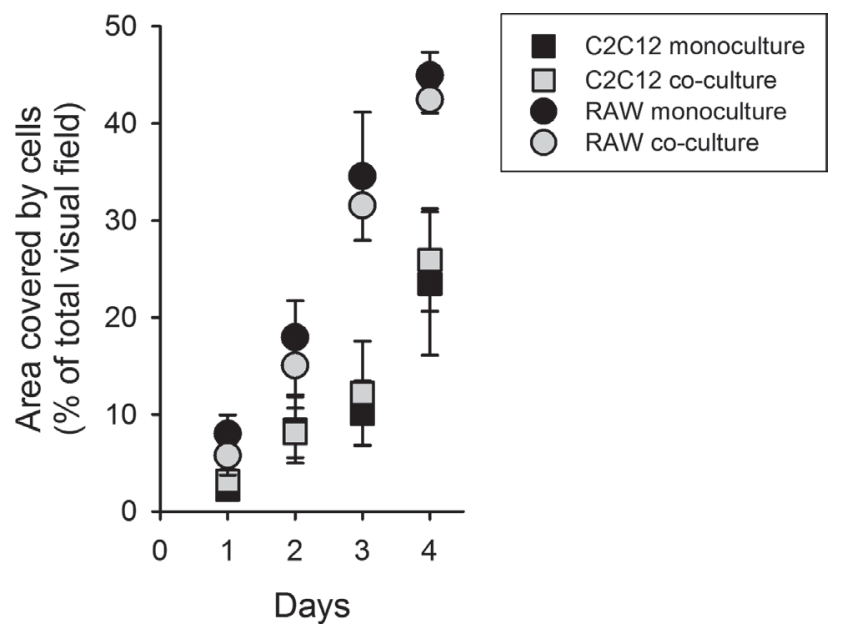

Figure 1. Proliferation of C2C12 muscle cells and RAW 264.7 macrophages in mono- and co-cultures. The number of cell cultures is 6. Averages are expressed as mean $\pm \mathrm{SD}$. than 0.05 was considered statistically significant. Graphpad Prism 6.0 software (GraphPad Software, San Diego, USA) was used for statistical analysis.

\section{Results}

Proliferation was not affected by co-culturing of RAW 264.7 macrophages and C2C12 muscle cells

To study the effects of two cell types on each other, proliferation of C2C12 myoblasts and RAW 264.7 macrophages was examined in mono- and co-culture (Fig. 1). One day after seeding the area covered by $\mathrm{C} 2 \mathrm{C} 12$ cells was $2.3 \pm 0.9 \%$ in monoculture and $3.1 \pm 1.2 \%$ in co-culture $(p>0.05)$, and in case of RAW 264.7 cells it was $8.0 \pm 1.9 \%$ in monoculture and $5.8 \pm 2.0 \%$ in co-culture $(p>0.05)$, respectively. On day 3 the difference between the two cell types was more
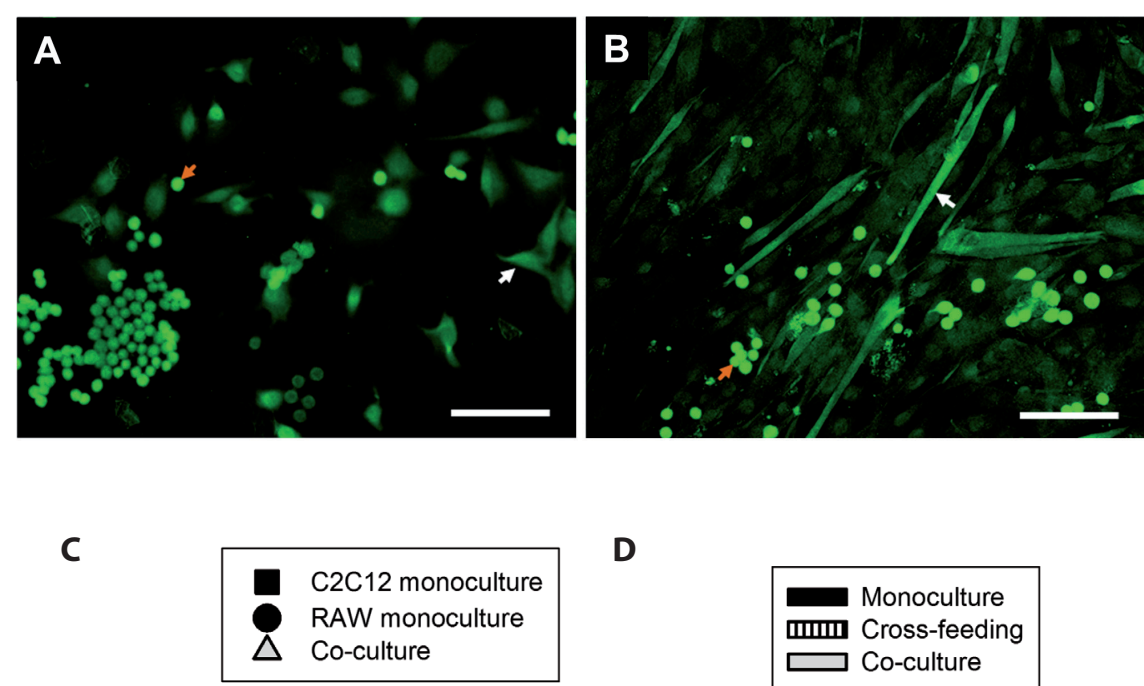

D

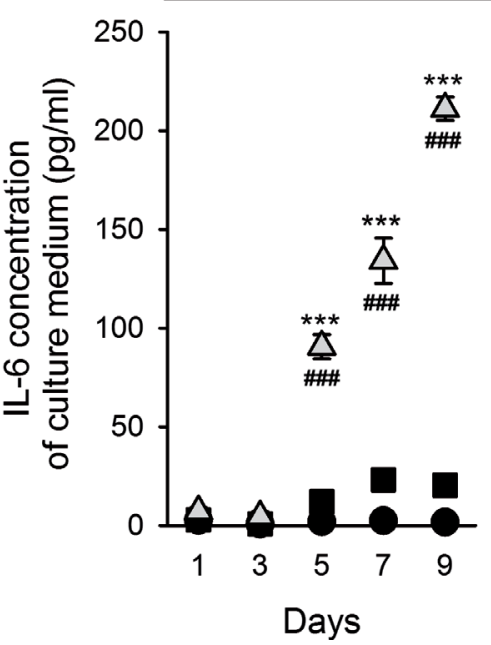

Figure 2. IL-6 production of mono- and co-cultures of $\mathrm{C} 2 \mathrm{C} 12$ muscle and RAW 264.7 macrophage cells. A. Immunofluorescent staining of IL-6 in proliferating C2C12 myoblasts and RAW 264.7 cells in 3-day co-culture. B. Differentiating $\mathrm{C} 2 \mathrm{C} 12$ myotubes and RAW 264.7 macrophages in 6-day co-culture. Scale bars represent $100 \mu \mathrm{m}$. White arrows point to an undifferentiated myoblast and a differentiated myotube, while red arrows to RAW 264.7 macrophages (panels A and B, respectively). C. IL-6 concentration in the culture medium of mono- and co-cultures at 1-9 days. $n=3$ cultures in all conditions. D. IL- 6 concentration of culture medium of C2C12 and RAW 264.7 cell cultures $24 \mathrm{~h}$ after the „cross-feeding”, on day 6. Number of cell cultures is 4 . Averages are expressed as mean $\pm \mathrm{SD}$; ${ }^{\star * *}$ significant difference from $\mathrm{C} 2 \mathrm{C} 12$ monoculture at

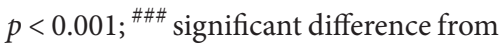
RAW monoculture at $p<0.001$; n.s., non-significant difference at $p>0.05$. 
prominent, the area covered by C2C12 cells was $10.1 \pm 3.4 \%$ in monoculture and $12.1 \pm 5.4 \%$ in co-culture $(p>0.05)$ and in case of RAW 264.7 cells it was $34.6 \pm 6.6 \%$ in monoculture and $31.6 \pm 3.6 \%$ in co-culture $(p>0.05)$. Rate of RAW 264.7 cells proliferation was significantly higher than $\mathrm{C} 2 \mathrm{C} 12$ cells from day 3 of culturing both in monoculture $(p<0.0001)$ and co-culture $(p<0.0001)$. On the other hand, co-culturing had no effect on the rate of cell division neither for myoblasts nor for macrophages $(p>0.05)$.

\section{IL-6 production is enhanced in co-culture of C2C12 and RAW 264.7 cells}

By using immunostaining method to detect IL-6 production in co-culture of C2C12 and RAW 264.7 cells, IL-6 production was found in both myogenic cells and monocytes/ macrophages in the proliferation and differentiation phase of myogenesis (Fig. 2A,B). Monitoring the IL-6 content in the culture medium showed low level of IL- 6 release without significant difference between the monocultures and coculture during proliferation phase of myogenesis (1-3 days) of culturing (Fig. 2C). On day 5 IL-6 concentration in cocultures started to elevate gradually while it remained low in both monocultures. The amount of released IL- 6 increased even further and was significantly higher compared to monocultures on day 7 and 9. Even though both $\mathrm{C} 2 \mathrm{C} 12$ and RAW 264.7 cells can release measurable amount of IL-6, its level remained low in the culture medium of monocultures during the 9-day culturing period.

Intensive cytokine production requires direct cell-cell connection between the two cell types

Besides IL-6 visualization by immunostaining, "cross-feeding" experiments were carried out and IL-6 concentration was measured. Both cell types released a certain amount of inflammatory cytokine on day 6 of culturing (C2C12 cells $1.6 \pm 0.1 \mathrm{pg} / \mathrm{ml}, \mathrm{C} 2 \mathrm{C} 12$ cells in RAW 264.7 culture medium $1.4 \pm 0.2 \mathrm{pg} / \mathrm{ml}$, RAW 264.7 cells $1.7 \pm 0.8 \mathrm{pg} / \mathrm{ml}$, RAW 264.7 cells in C2C12 culture medium $1.2 \pm 0.3 \mathrm{pg} / \mathrm{ml}$ ). Monocultures did not release more IL- 6 neither in fresh medium nor in medium derived from the culture of the other cell type $(p>0.05)$. Significantly higher IL-6 secretion of co-cultures $(55.3 \pm 9.0 \mathrm{pg} / \mathrm{ml})$ was found in comparison to monocultures (Fig. 2D).

\section{Pravastatin enhances IL-6 production of co-culture}

Since statins have been shown to reduce inflammation, we hypothesized that the water-soluble pravastatin would decrease IL-6 level in co-cultures. To test this hypothesis, we treated 6-day-old monocultures and co-cultures with $500 \mu \mathrm{M}$ pravastatin for $24 \mathrm{~h}$ (Fig. 3). However, in contrast to our hypothesis, we observed that pravastatin significantly increased IL- 6 production in C2C12 monocultures (control $2.3 \pm 0.2 \mathrm{pg} / \mathrm{ml}$; pravastatin treated $18.0 \pm 1.5 \mathrm{pg} / \mathrm{ml}, p<$ 0.001 ) and in co-cultures as well (control $129.3 \pm 5.8 \mathrm{pg} /$ $\mathrm{ml}$; pravastatin $945.8 \pm 50.2 \mathrm{pg} / \mathrm{ml} ; p<0.001$ ) and did not modify considerably the IL- 6 production of RAW 264.7 monocultures (control $2.5 \pm 0.1 \mathrm{pg} / \mathrm{ml}$; pravastatin $1.8 \pm$ $0.1 \mathrm{pg} / \mathrm{ml} ; p>0.05)$.

Pravastatin significantly impairs the proliferative ability of C2C12 muscle cells

We then hypothesized that increased IL- 6 production of coculture might originate from the increased number of cells due to pravastatin treatment. Thus, we examined the proliferation of 24-hour-old monocultures treated with pravastatin. Number of myoblasts decreased significantly after $24 \mathrm{~h}$ pravastatin treatment (Fig. 4A,B; $p<0.01$ ). In contrast, to that number of macrophages was unchanged after $24 \mathrm{~h}$ treatment (Fig. 4C,D; $p>0.05)$. Thus, it is unlikely that the elevated IL- 6 level in the co-culture after pravastatin treatment is the result of enhanced proliferation capacity of cells (Fig. 4E,F).

\section{Pravastatin impairs C2C12 differentiation}

Since pravastatin has a considerable negative effect on the proliferation of $\mathrm{C} 2 \mathrm{C} 12$ cells, we studied the effects of pravas-

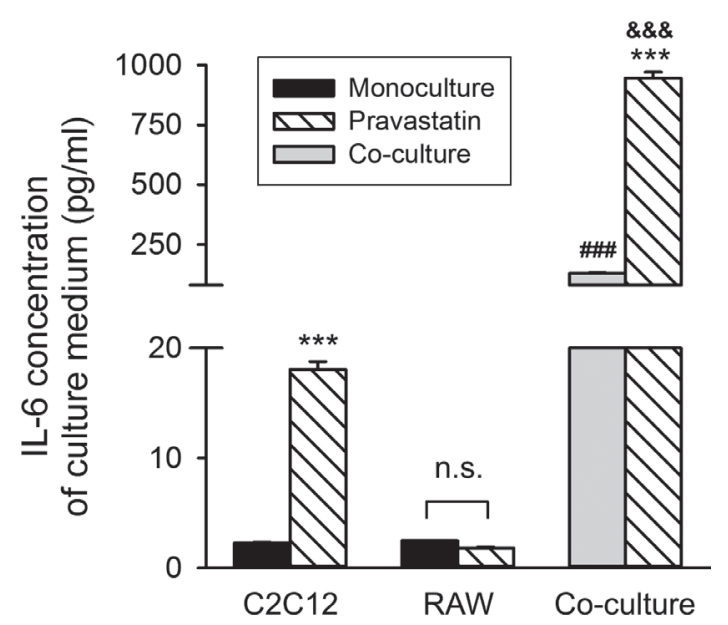

Figure 3. IL- 6 concentration of culture medium of $\mathrm{C} 2 \mathrm{C} 12$ and RAW 264.7 cells in mono- and co-cultures at day 7, under control conditions and $24 \mathrm{~h}$ after pravastatin treatment. Number of cell culture is 4 . Averages are expressed as mean $\pm \mathrm{SD}$; ${ }^{\star * *}$ significant difference between non-treated and pravastatin-treated cultures at $p<0.001 ;{ }^{\# \#}$ significant difference between non-treated monoand co-cultures at $p<0.001 ;$ \&\&\& significant difference between pravastatin-treated mono- and co-cultures at $p<0.001$; n.s., no significant difference at $p>0.05$. 
tatin on differentiation, too (Fig. 5A,B). Fusion index (FI) represents the ratio of nuclei in myotubes to all nuclei in the cell culture. Differentiating C2C12 cells were treated with pravastatin for 9 days, and we detected significantly lower number of myotubes $(p<0.05)$ on the $7^{\text {th }}$ and $9^{\text {th }}$ days of culturing than in untreated cultures (Fig. 5C). While fusion index of control cells showed gradual increase from day 5 to 9 , treated values has not been changed at all. However, pravastatin treated cultures had similar $(p>0.3)$ viability to those under control conditions (Fig. 5D).

\section{Discussion}

Interaction between skeletal muscle and macrophages is a very important factor in skeletal muscle growth both under physiological and pathological conditions as well.
In our experiments co-cultures of RAW 264.7 murine macrophages and $\mathrm{C} 2 \mathrm{C} 12$ mouse myoblasts were used as an in vitro model for normal regeneration and inflammatory myopathy.

We found that proliferation rate of myoblasts was lower than that of macrophages in separated monocultures. Coculturing did not alter the proliferation of myoblasts or macrophages in the phase of proliferation (in the first 4 days) when isolated myoblasts or small myotubes were the dominant cell types. This finding indicates that at this phase of myogenesis in an immortalized cell line there is no significant cytokine release neither from myogenic nor from myeloid cells that would increase the rate of proliferation.

Chazaud and coworkers (2003) reported that macrophages increased the rate of proliferation in primary human muscle culture by soluble factors and by direct contact. They focused on the chemotactic soluble factors released
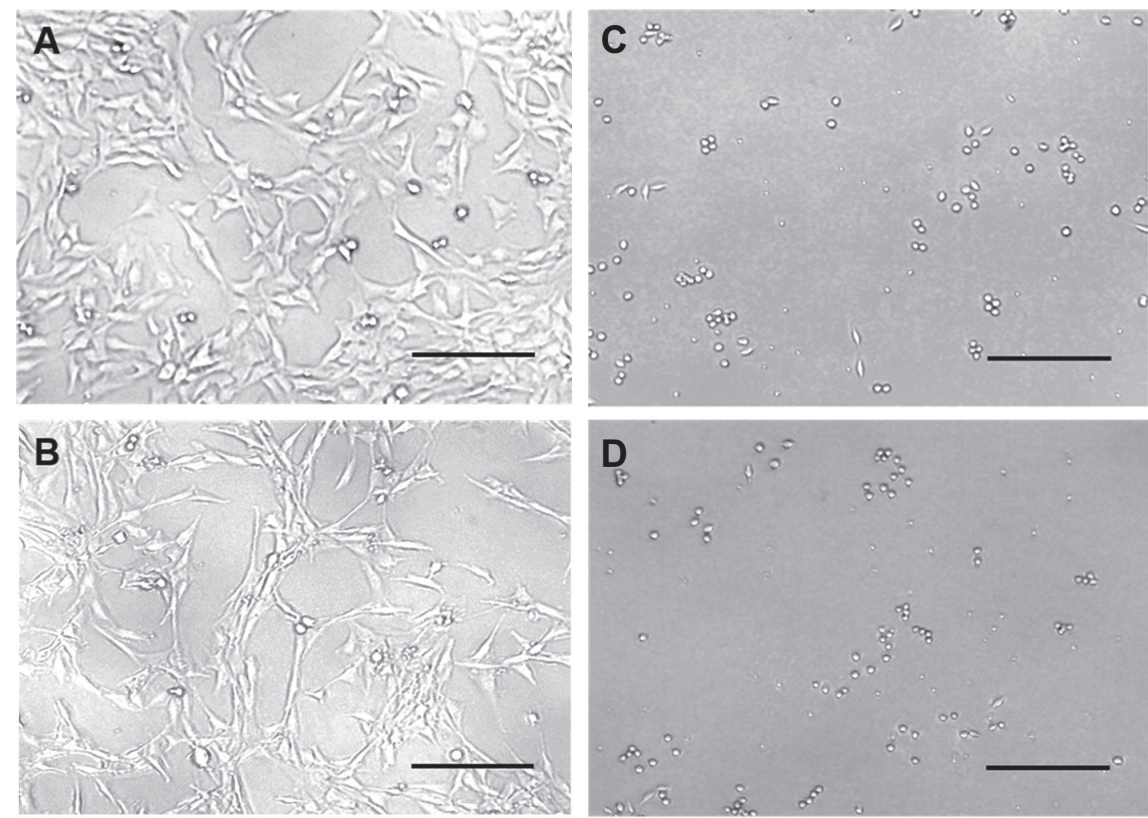

E
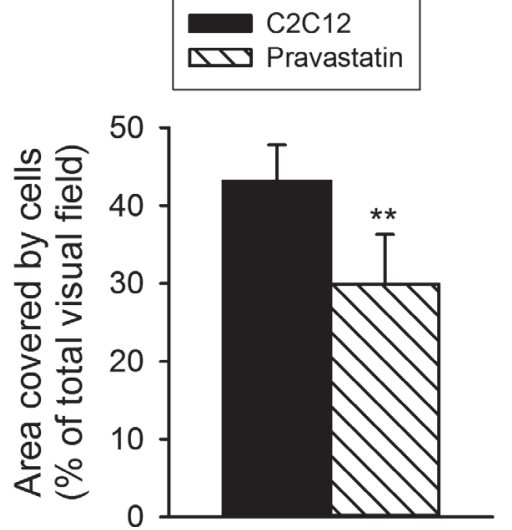

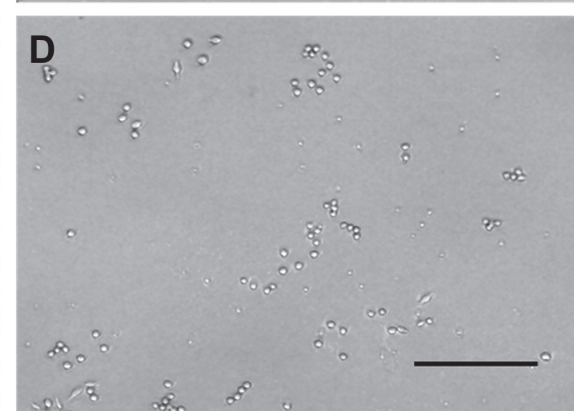

$\mathbf{F}$

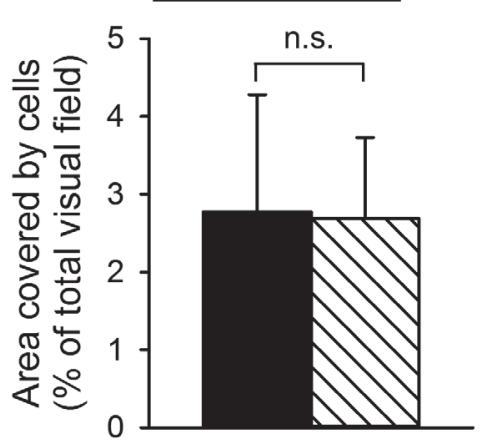

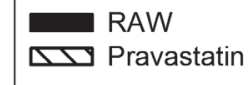

Figure 4. The effect of pravastatin on the proliferation of $\mathrm{C} 2 \mathrm{C} 12$ myoblasts and RAW 264.7 macrophages. Transmitted light images of non-treated (A) and $500 \mu \mathrm{M}$ pravastatin-treated (B) $\mathrm{C} 2 \mathrm{C} 12$ cells, non-treated $(\mathrm{C})$ and $500 \mu \mathrm{M}$ pravastatin-treated (D) RAW 264.7 cells in 1-day-old cell culture. Scale bars represent $100 \mu \mathrm{m}$. Relative area (\% of visual fields) covered by $\mathrm{C} 2 \mathrm{C} 12$ cells (E) and RAW 264.7 cells (F) in monocultures. Number of cell cultures is 6 and number of visual field examined is 5 in each culture. Averages are expressed as mean $\pm \mathrm{SD}$; ${ }^{* *}$ significant difference at $p<0.01$; n.s., non-significant. 

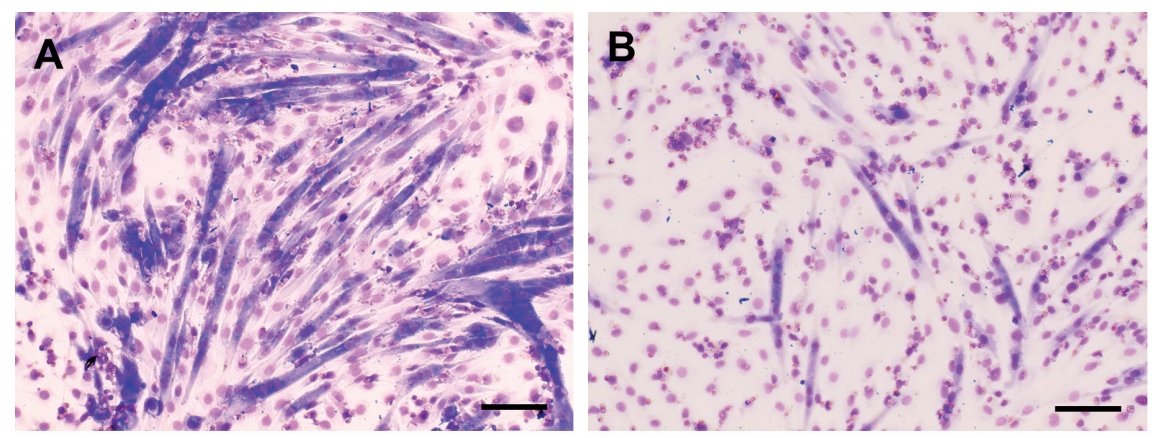

C

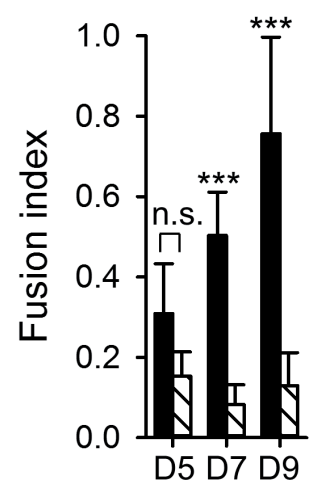

D

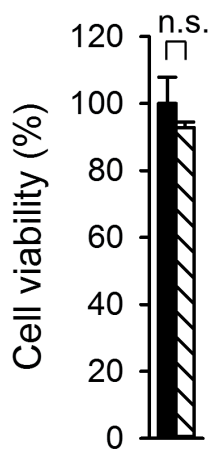

Figure 5. The effect of pravastatin on the differentiation of $\mathrm{C} 2 \mathrm{C} 12$ myotubes. Light microscopic images of MayGrünwald-Giemsa stained non-treated (A) and $500 \mu \mathrm{M}$ pravastatin-treated (B) C2C12 cells in a 7-day-old differentiating cell culture. Scale bars correspond to $100 \mu \mathrm{m}$. C. Fusion index of pravastatin-treated $\mathrm{C} 2 \mathrm{C} 12$ cells compared to control cells at day 5 (D5), 7 (D7), and 9 (D9) of the differentiation. D. MTT assay for cell viability of pravastatintreated and control C2C12 cells on day 7 of culturing. Averages are expressed as mean $\pm \mathrm{SD} ;{ }^{* * *}$ significant difference at $p<0.001 ;$ n.s., no significant difference at $p>0.05$. from satellite cells and proliferating myoblasts but did not define the possible soluble factors acting on myogenic cell proliferation. Increase in cell density was rendered to the attenuated apoptosis of myogenic cells evoked by direct cell-to-cell contact between myogenic cells and monocytes.

IL- 6 can be one of the cytokines that could be released from both myogenic cells, monocytes and macrophages as well, and can play important role in the interactions between two cell types during muscle regeneration (Cantini et al. 1995). It was proved by Serrano and coworkers (2008) that IL-6 can be the key regulator in the satellite cell-mediated skeletal muscle hypertrophy.

We detected IL-6 release from both $\mathrm{C} 2 \mathrm{C} 12$ and RAW cells at a measurable level from the beginning of culturing in monocultures. Despite the lower proliferation rate, $\mathrm{C} 2 \mathrm{C} 12$ cells secreted more IL- 6 from day 5 of the culturing than macrophages. IL- 6 production was significantly elevated in the co-cultures. We confirmed the IL-6 production in co-culture both in the myogenic cells and macrophages by immunostaining, but due to the methodological reason (the myoblasts and macrophages were not separated in these experiments) the participation of the muscle cells and the macrophages in the IL-6 release cannot be distinguished. Since the exchange of the culture medium between the two monocultures ("crossfeeding") did not prove the role of some soluble factors in the increased IL- 6 secretion in the co-culture, a cell-to-cell contact or a paracrine mechanism acting at a limited distance must be hypothesized. However, the explanation for considerably higher IL-6 production in co-cultured cells in comparison to the monocultures needs further analysis. Our results prove the interaction between myogenic and myeloid cells during the regeneration process of skeletal muscle.

Based on our previous experiments (Cseri et al. 2015) and data from the literature (Andersson et al. 2000; De Mori et al. 2007; Ghosh and Ghosh 2020), we suggest that HMGB1 (High-Mobility Group Box-1) can be a possible candidate to mediate the interaction between cells in co-culture. It was reported that HMGB1 stimulated cytokine (i.e. IL-6) production in human monocytes (Andersson et al. 2000). It can be a regulator in the muscle-macrophage crosstalk during chronic inflammatory processes (Ghosh and Ghosh 2020) and is a chemotactic factor in the myoblast migration (De Mori et al. 2007). In our preliminary experiments, nuclear localization of HMGB1 in satellite cells, myoblasts and myotubes as well as in macrophages was detected either in mono- or in co-cultures (unpublished data). Quantitative analysis of HMGB1 concentration in the culture medium and possible correlation between HMGB1 and IL-6 concentration awaits further studies.

Statins are known as to have multiple effects, i.e. reduce the cholesterol level in the blood and have anti-inflammatory effect. Beside the advantages, statin-induced myopathy can 
turn into as adverse effect of these drugs. Since IL-6 is known as a proinflammatory cytokine, inhibitory effect of pravastatin on IL- 6 production was expected in co-culture. In contrast, pravastatin increased IL- 6 production in $\mathrm{C} 2 \mathrm{C} 12$ monocultures and in co-cultures of $\mathrm{C} 2 \mathrm{C} 12$ and RAW cells. On the other hand, IL- 6 production of macrophages was unaltered in 6-day-old monocultures. Although, the separation of source of IL- 6 in our co-culture is impossible due to methodological reasons, it is possible that higher IL-6 secreting activity of myogenic cells is reflected in the enhanced IL-6 concentration of pravastatin treated co-cultures.

It has been reported that statin treatment does not alter the cytokine production of monocytes but increases it in differentiated macrophages (Fu et al. 2019). Ineffectiveness of pravastatin on RAW 264.7 monoculture in our experiment may indicate that most cells were monocytes and not differentiated macrophages in the absence of stimulation. Stimulating the mononuclear cells by lipopolysaccharide and applying pravastatin, synergism of IL- 6 production in co-culture was found when human vascular muscle cells and human mononuclear cells were cultured together (Loppnow et al. 2011).

Pravastatin was found to reduce the proliferation of $\mathrm{C} 2 \mathrm{C} 12$ cells in monoculture but did not influence cell density of RAW 264.7 in monoculture in present experiments. Pravastatin inhibited the fusion of myoblasts into myotubules in the stage of differentiation. Fusion index was considerably lower in the presence of pravastatin compared to untreated cultures at day 7-9 of culturing. Viability of myogenic cells was not affected by pravastatin treatment. This may indicate impaired regeneration in inflammatory myopathies due to the inhibited differentiation and not the decreased viability of cells.

Similar results were reported from our laboratory, namely the fluvastatin treatment decreased the proliferation and fusion of skeletal myotubes in primary cultures derived from hypercholesterolemic rats (Füzi et al. 2012). In agreement with our findings the lipophilic rosuvastatin and simvastatin impaired the myoblast proliferation in primary cultures derived from human skeletal muscle, and simvastatin delayed the differentiation (Grunwald et al. 2020).

The exact pathomechanism of statin-induced toxic myopathy is not known but presumably the lack of essential metabolites and destabilized membrane integrity may result in myotoxicity (Evans and Rees 2002). In addition, it was shown by our laboratory that statin treatment has negative effects on calcium homeostasis resulting in impaired force generation in rat skeletal muscle (Vincze et al. 2015).

\section{Conclusion}

In conclusion, our data give further evidence to understand the very complex interactions between muscle and mac- rophages in the regeneration of skeletal muscle following muscle damage and effects of macrophages in inflammatory myopathies. We suggest that there is intricate interaction between muscle cells and macrophages in the regulation of their IL-6 production which results in an elevated IL-6 concentration in the extracellular milieu. Furthermore, the observation that pravastatin altered the IL- 6 production raises the possibility of the involvement of mevalonate pathway in this process. Additional experiments are necessary to explore the details of underlying mechanisms.

Acknowledgement. Authors are indebted to Róza Őri and Mónika Kovács for their technical assistance. The authors thank Julianna Cseri for valuable discussion on the manuscript. The research was supported by the Thematic Excellence Program (TKP2020NKA-04) of the Ministry for Innovation and Technology in Hungary.

Author contribution. Conceived and designed the experiments: KC, LC. Performed the experiments: KC, PS. Analyzed the data: KC, PS. Wrote the manuscript: KC, PS, LC.

Conflict of interest. The authors have declared that no competing interests exist.

Data availability. The datasets generated and analyzed during the current study are available from the first author on reasonable request.

\section{References}

Andersson U, Wang $\mathrm{H}$, Palmblad K, Aveberger AC, Bloom O, Erlandsson-Harris H, Janson A, Kokkola R, Zhang M, Yang H, Tracey KJ (2000): High mobility group 1 protein (HMG-1) stimulates proinflammatory cytokine synthesis in human monocytes. J. Exp. Med. 192, 565-570 https://doi.org/10.1084/jem.192.4.565

Cantini M, Carraro U (1995): Macrophage-released factor stimulates selectively myogenic cells in primary muscle culture. J. Neuropathol. Exp. Neurol. 54, 121-128 https://doi.org/10.1097/00005072-199501000-00014

Cantini M, Massimino ML, Rapizzi E, Rossini K, Catani C, Dalla Libera L, Carraro U (1995): Human satellite cell proliferation in vitro is regulated by autocrine secretion of IL- 6 stimulated by a soluble factor(s) released by activated monocytes. Biochem. Biophys. Res. Commun. 216, 49-53 https://doi.org/10.1006/bbrc.1995.2590

Carson JA, Baltgalvis KA (2010): Interleukin-6 as a key regulator of muscle mass during cachexia. Exerc. Sport Sci. Rev. 38, 168-176 https://doi.org/10.1097/JES.0b013e3181f44f11

Chazaud B, Sonnet C, Lafuste P, Bassez G, Rimaniol AC, Poron F, Authier FJ, Dreyfus PA, Gherardi RK (2003): Satellite cells attract monocytes and use macrophages as a support to escape apoptosis and enhance muscle growth. J. Cell Biol. 163, 1133-1143 https://doi.org/10.1083/jcb.200212046 
Cseri K, Vincze J, Cseri J, Fodor J, Csernátony Z, Csernoch L, Dankó K (2015): HMGB1 expression and muscle regeneration in idiopathic inflammatory myopathies and degenerative joint diseases. J. Muscle Res. Cell Motil. 36, 255-262 https://doi.org/10.1007/s10974-015-9411-7

Dalakas MC (2009): Toxic and drug-induced myopathies. Neurol. Neurosurg. Psychiatry 80, 832-838 https://doi.org/10.1136/jnnp.2008.168294

Davidson MH, Stein EA, Dujovne CA, Hunninghake DB, Weiss SR, Knopp RH, Illingworth DR, Mitchel YB, Melino MR, Zupkis RV, et al. (1997): The efficacy and six-week tolerability of simvastatin 80 and $160 \mathrm{mg}$ /day. Am. J. Cardiol. 79, 38-42 https://doi.org/10.1016/S0002-9149(96)00742-4

De Mori R, Straino S, Di Carlo A, Mangoni A, Pompilio G, Palumbo R, Bianchi ME, Capogrossi MC, Germani A (2007): Multiple effects of high mobility group box protein 1 in skeletal muscle regeneration. Arterioscler. Thromb. Vasc. Biol. 27, 2377-2383 https://doi.org/10.1161/ATVBAHA.107.153429

Dort J, Fabre P, Molina T, Dumont NA (2019): Macrophages are key regulators of stem cells during skeletal muscle regeneration and diseases. Stem Cells Int. 2019, 4761427 https://doi.org/10.1155/2019/4761427

Dumont NA, Bentzinger CF, Sincennes MC, Rudnicki MA (2015) Satellite cells and skeletal muscle regeneration. Compr. Physiol. 5, 1027-1059 https://doi.org/10.1002/cphy.c140068

Evans M, Rees A (2002): Effects of HMG-CoA reductase inhibitors on skeletal muscle: Are all statins the same? Drug Saf. 25, 649-663 https://doi.org/10.2165/00002018-200225090-00004

Fu H, Alabdullah M, Großmann J, Spieler F, Abdosh R, Lutz V, Kalies K, Knöpp K, Rieckmann R, Koch S, et al (2019): The differential statin effect on cytokine production of monocytes or macrophages is mediated by differential geranylgeranylationdependent Rac1 activation. Cell Death Dis. 10, 880 https://doi.org/10.1038/s41419-019-2109-9

Füzi M, Palicz Z, Vincze J, Cseri J, Szombathy Z, Kovács I, Oláh A, Szentesi P, Kertai P, Paragh G, Csernoch L (2012): Fluvastatininduced alterations of skeletal muscle function in hypercholesterolaemic rats. J. Muscle Res. Cell Motil. 32, 391-401 https://doi.org/10.1007/s10974-011-9272-7

Ghosh SS, Ghosh S (2020): HMGB1 (high-mobility group box-1): a common link determining the consequences of tissue injury, sterile/microbial and low-grade chronic inflammation. Arterioscler. Thromb. Vasc. Biol. 40, 2561-2563

https://doi.org/10.1161/ATVBAHA.120.315189

Grunwald SA, Popp O, Haafke S, Jedraszczak N, Grieben U, Saar K, Patone G, Kress W, Steinhagen-Thiessen E, Dittmar G, Spuler S (2020): Statin-induced myopathic changes in primary human muscle cells and reversal by a prostaglandin F2 alpha analogue. Sci. Rep. 10, 2158 https://doi.org/10.1038/s41598-020-58668-2

Loppnow H, Zhang L, Buerke M, Lautenschläger M, Chen L, Frister A, Schlitt A, Luther T, Song N, Hofmann B, et al. (2011): Statins potently reduce the cytokine-mediated IL-6 release in SMC/ MNC co-cultures. J. Cell Mol. Med. 15, 994-1004 https://doi.org/10.1111/j.1582-4934.2010.01036.x
Merely F, Lescaudron L, Rouaud T, Crossin F, Gardahaut MF (1999): Macrophages enhance muscle satellite cell proliferation and delay their differentiation. Muscle Nerve 22, 724-732 https://doi.org/10.1002/(SICI)1097-4598(199906)22:6<724::AID-MUS9>3.0.CO;2-O

Nag AC, Foster JD (1981): Myogenesis in adult mammalian skeletal muscle in vitro. J. Anat. 132, 1-18

Nazir S, Lohani S, Tachamo N, Poudel D, Donato A (2017): Statinassociated autoimmune myopathy: A systematic review of 100 cases. J. Clin. Rheumatol. 23, 149-154 https://doi.org/10.1097/RHU.0000000000000497

Pasnoor M, Barohn RJ, Dimachkie MM (2014): Toxic myopathies. Curr. Opin. Neurol. 31, 575-582 https://doi.org/10.1097/WCO.0000000000000606

Pillon NJ, Bilan, PJ, Fink LN, Klip A (2013): Cross-talk between skeletal muscle and immune cells: muscle-derived mediators and metabolic implications. Am. J. Physiol. Endocrinol. Metab. 304, E453-465 https://doi.org/10.1152/ajpendo.00553.2012

Serrano AL, Baeza-Raja B, Perdiguero E, Jardí M, Muñoz-Cánoves $P$ (2008): Interleukin-6 is an essential regulator of satellite cellmediated skeletal muscle hypertrophy. Cell Metabolism 7, 33-44 https://doi.org/10.1016/j.cmet.2007.11.011

Stenzel W, Goebel HH, Aronica E.(2012): Review: Immunemediated necrotizing myopathies - a heterogeneous group of diseases with specific myopathological features. Neuropathol. Appl. Neurobiol. 38, 632-646 https://doi.org/10.1111/j.1365-2990.2012.01302.x

Tidball JG, Villalta SA (2010): Regulatory interactions between muscle and the immune system during muscle regeneration. Am. J. Physiol. Regul. Integr. Comp. Physiol. 298, R1173-R1187 https://doi.org/10.1152/ajpregu.00735.2009

Thompson PD, Clarkson P, Karas RH (2003): Statin-associated myopathy. JAMA 289, 1681-190

https://doi.org/10.1001/jama.289.13.1681

Vincze J, Jenes Á, Füzi M, Almássy J, Németh R, Szigeti G, Dienes B, Gaál Z, Szentesi P, Jóna I, et al. (2015): Effects of fluvastatin and coenzyme Q10 on skeletal muscle in normo- and hypercholesterolaemic rats. J. Muscle Res. Cell Motil. 36, 263-274 https://doi.org/10.1007/s10974-015-9413-5

Walsh RJ, Amato AA (2005): Toxic myopathies. Neurol. Clin. 23, 397-428 https://doi.org/10.1016/j.ncl.2004.12.014

Wang X, Wu H, Zhang Z, Liu S, Yang J, Chen X, Fan M, Wang X (2008): Effects of interleukin-6, leukemia inhibitory factor, and ciliary neurotrophic factor on the proliferation and differentiation of adult human myoblasts. Cell Mol. Neurobiol. 28, 113-124 https://doi.org/10.1007/s10571-007-9247-9

Wosczyna MN, Rando TA (2018): A muscle stem cell support group: coordinated cellular responses in muscle regeneration. Dev. Cell. 46, 135-143 https://doi.org/10.1016/j.devcel.2018.06.018

Yin H, Price F, Rudnicki MA (2013): satellite cells and the muscle stem cell niche. Physiol. Rev. 93, 23-67 https://doi.org/10.1152/physrev.00043.2011

Received: March 3, 2021

Final version accepted: May 20, 2021 